\title{
SUZUKI SHOKO: RELATO DA TRAJETÓRIA DE VIDA DE UMA MULHER CERAMISTA ENTRE O BRASIL E O JAPÃO
}

\section{Liliana Granja Pereira de Morais ${ }^{1}$}

Resumo: Neste artigo, pretende-se apresentar o relato pessoal da trajetória de vida da ceramista japonesa residente no Brasil, Suzuki Shoko, de acordo com os preceitos dos récits de vie definidos por Daniel Bertaux (1997). Partindo do conceito de Renato Ortiz (2000) da identidade como uma construção simbólica feita em relação a um referente, importa conhecer o contexto histórico, social e cultural em que a trajetória desta ceramista se insere. A situação da mulher japonesa no início da Era Shôwa (1929-1945), a experiência da Segunda Guerra Mundial, a emigração de artistas japoneses para o "Novo Mundo" e a apropriação da "tradição" nipônica no Brasil são elementos que irão permear o discurso desta ceramista, cuja trajetória é marcada pela vivência transcultural e por uma negociação constante da identidade na relação com o "outro"

Palavras-chave: cultura japonesa; identidade nikkei; cerâmica; tradição e memória; relato de vida.

\begin{abstract}
This article intends to present the life-story of Suzuki Shoko, a Japanese ceramic artist living in Brazil, following the precepts of the récits de vie as defined by Daniel Bertaux (2000). Based on Renato Ortiz's concept of identity as a symbolic construction made in relation to a referent (2000), it is important to know the historical, social and cultural context of these ceramist's trajectory. The role of the Japanese woman in the beginning of the Showa Era (1929-1945), the experience of the Second World War, the emigration of Japanese artists to the "New World" and the appropriation of the Japanese "tradition" in Brazil are elements that will permeate these ceramist's discourse, whose story is marked by the transcultural experience and by the constant negotiation of her identity in the relation with the "other"
\end{abstract}

Keywords: Japanese culture; nikkei identity; ceramics; tradition and memory; life-story.

1. Mestranda do Programa de Pós-Graduação em Língua, Literatura e Cultura Japonesa da Universidade de São Paulo. 


\section{Apresentação}

Este artigo é parte da minha pesquisa de mestrado sobre as representações da identidade japonesa no relato de vida de quatro mulheres ceramistas nikkei. Proponho-me aqui apresentar a trajetória de apenas uma delas, Suzuki Shoko. Hoje com 83 anos, Suzuki deixou o Japão quando tinha 32, em uma época que o movimento migratório em direção ao Brasil tomava um novo rumo.

A trajetória de Suzuki Shoko insere-se em um contexto histórico e sociocultural específico, que nos importa conhecer. Pois, como afirma Renato Ortiz (2000, p. 64), a identidade nada mais é que uma construção simbólica que se faz em relação a um referente. O referente corresponde, no caso de Suzuki, a duas realidades distintas. Por um lado, um Japão no início da Era Shôwa (1929-1945), caracterizado pelo ímpeto imperialista e nacionalista. Depois, um Japão derrotado na Segunda Guerra Mundial e ocupado por forças norte-americanas, democratizado e desmilitarizado, lutando pela modernização, crescimento econômico e afirmação nacional. Por outro lado, o Brasil, mais especificamente o Estado de São Paulo, para onde Suzuki imigrou na década de 1960, como vários outros artistas em busca de maior liberdade criativa. Um Brasil que passava por um rápido processo de desenvolvimento industrial e urbano. Uma capital paulistana habitada por pessoas de várias origens e nacionalidades, com uma forte presença da comunidade nipônica e em efervescência cultural e artística. A trajetória de vida de Suzuki Shoko insere-se então neste contexto, que será abordado como pano de fundo de seu relato pessoal.

Ademais, como mulher ceramista nascida no Japão pré-guerra, parece-nos imprescindível colocar algumas questões de gênero que foram surgindo ao longo das entrevistas. Veremos, portanto, como na cerâmica, a lógica patriarcal conservadora dificultou a trajetória de Suzuki como ceramista no Japão, gerando um desejo de libertação da rigidez da tradição. Este elemento "tradição" será também abordado ao longo do artigo, pois ele é indissociável da expressão artística da cerâmica e da identidade pessoal desta ceramista.

Importa frisar, todavia, que partirei, para esta análise, de vários conceitos-chave da antropologia pós-moderna e da teoria cultural. Ao falarmos de cultura japonesa referimo-nos a um discurso composto de símbolos e representações, tal como definido por Stuart Hall (1992, p. 13), discurso esse que produz identidades, ou seja, sentidos sobre a nação com os quais nos podemos identificar. Também a ideia de tradição, refletida na continuidade das técnicas da cerâmica no Japão, nada mais é que uma "tradição inventada" tal como definida por Eric Hosbawm (1983), que toma importante papel na construção de uma identidade cultural japonesa no período moderno.

A identidade de Suzuki Shoko, como mulher ceramista nikkei, constrói-se então a partir desses conceitos ("cerâmica japonesa", "tradição"), discursos ("cultura", "nação") e representações (Japão, Brasil). Como elemento fluído, múltiplo e 
situacional, além de histórica, social e politicamente marcado, a identidade desta ceramista, caracterizada pela vivência transcultural, é constantemente negociada na relação com o "outro", seja este brasileiro ou japonês. Partindo destas considerações, pretendi afasta-me de análises essencialistas e estereotipadas, mas apresentar o discurso de Suzuki sempre em diálogo com o contexto histórico e social em que sua trajetória se insere.

O relato de vida de Suzuki Shoko foi obtido por meio de entrevistas qualitativas efetuadas no final de 2011, seguindo os preceitos etnossociológicos dos récits de vie definidos por Daniel Bertaux (1997). Este método etnográfico consiste basicamente na análise do relato, sempre subjetivo, da história de vida de um ou mais entrevistados, a partir de uma perspectiva sociológica, de forma a compreender um determinado fenômeno social.

\section{Suzuki Shoko: um relato da trajetória de vida}

Suzuki Shoko nasceu em Tóquio no dia 26 de abril de 1929 sob o nome de Oshima Akiko Shoko, única filha de uma família aristocrática descendente de samurai. A casa onde cresceu era frequentada por vários médicos, pois seu pai era funcionário público do Instituto de Medicina do Japão, o que impulsionou na jovem Suzuki o desejo de explorar a medicina quando crescesse. Sua mãe, sobre quem evita falar, faleceu quando tinha oito anos de idade; Suzuki foi então criada pela madrasta, com a quem não tinha muita afinidade. Estas duas importantes presenças femininas na sua infância foram ambas donas de casa (shufu), refletindo o papel que era esperado das mulheres japonesas naquela época, principalmente as de classe mais alta. Yoshimoto Midori (2006, p. 2) escreve que a sociedade japonesa permitia poucas alternativas ao papel tradicional da mulher como ryôsai kenbo (boas esposas e mães sábias). Logo, como a mulher japonesa da época devia evitar o trabalho fora de casa, dedicando-se ao marido e às atividades domésticas, a educação das meninas era também voltada para que elas exercessem essa função. Suzuki, durante a entrevista, fez vários comentários a esse respeito.

Não conhecia quase ninguém que trabalhasse fora. Naquela época, desprezava-se mulher que trabalhava fora. (...) Depois eu conheci algumas, como elas lutavam. (...) Quando ficava viúva, mulher podia costurar quimono. Tinha outras profissões também, como professora de koto. Sempre tinha. Mas as pessoas não consideravam aquilo profissão. Era hobby. (...). Quando fazem 18 anos, por aí, as meninas vão na casa dos amigos dos pais e preparam esse dia [de casamento], aprendendo a cozinhar, costurar, não sei, alguma coisa assim. Meu pai falava também: "quando você ficar grande...", que tinha amigo muito bom. Dizia: "aquela casa você fica junto antes de casar" Nossa, graças a deus que acabou antes! 
Suzuki cresceu na cidade de Yokohama, perto de Tóquio, durante o início da Era Shôwa (1926-1945), período em que se assistiu ao aumento do nacionalismo, militarismo e totalitarismo no Japão. Essa época foi marcada pela continuação da modernização e ocidentalização iniciada com a Reforma Meiji (1868-1912), mas também pela crise econômica decorrente da Grande Depressão americana de 1929. As contínuas agressões contra a China e outros países do Sudeste Asiático por parte do Japão, levaram ao desencadear da Guerra Sino-Japonesa em 1937, que culminaria na entrada do Japão na Segunda Guerra Mundial em 1941, após o ataque a Pearl Harbor. Foi nesta turbulenta conjuntura que Suzuki Shoko viveu sua infância e adolescência.

Guerra é culpa de todo o mundo, não só americano ou japonês.

Quando a entrevistei no dia 11 de novembro de 2011, após vários outros contatos, Suzuki recusou-se, inicialmente, a falar sobre a sua vida no Japão, principalmente sobre a infância e a guerra. Seu desejo era começar do zero em outro país, deixando para trás todos os acontecimentos do passado, como se a memória fosse algo possível de apagar.

Isso na verdade eu não quero falar muito. Sabe por quê? Acho que você compreende...

(...) Eu não quero falar detalhadamente sobre infância, como guerra... Eu queria sair

do Japão só, nada de história, vir para cá... assim... colocar meu pé aqui onde está e zero. Acho que você entende...

No entanto, ao longo da entrevista, Suzuki acabou contando vários detalhes sobre a sua infância no período da guerra. Quando lhe perguntei sobre seu interesse por cerâmica, relatou um episódio que sucedeu após sua casa ter sido destruída por um bombardeio americano no dia 29 de maio de 1944, um ano antes de terminar a Segunda Guerra Mundial:

No dia seguinte [ao bombardeio] (...) caminhando, caminhando, ainda estava muita fumaça. E, quando passei, um senhor de idade estava "cavocando" no fundo, alguma coisa. Quando eu passei, eu me arrepiei muito! Era alguma coisa. Mas quando vi era alguma coisinha assim [fez pequeno gesto com a mão]. Então, eu não vi se era cerâmica. Mas alguma coisa, depois, me parece, era cerâmica... eu senti vida. (...). Quando eu penso naquela cena me arrepia e penso na vida. Isso sempre ficou comigo. Aí vocês [pesquisadores] sempre me perguntam por que eu gostei de cerâmica. E eu comecei a perguntar: "por quê será?" Era natureza.

Suzuki associa esse episódio, em que viu nos destroços do bombardeio um resquício de vida em um objeto que pensou ser uma cerâmica, ao início do seu interesse por essa expressão artística, o que remete para a teoria da arte como sublimação. A desilusão com a essência do ser humano perante a brutalidade da 
guerra e a experiência da completa destruição da sua casa impulsionou em Suzuki o desejo de sair do Japão, mas também uma vontade de explorar o cerne do espírito humano, traduzido na relação com a cerâmica. Esta, por implicar o uso e a transformação da argila, é por ela associada à força da terra, que lhe remete para a natureza e para a imagem feminina e acolhedora da "grande mãe"

Sobre meu trabalho, eu tenho que falar, infelizmente, de guerra... porque, também é um motivo que [me fez querer] aprofundar a situação de como é humano e dúvida sobre a vida. (...) [Quando era jovem] eu gostava de passar em antiquários. Olhava e via muitas coisas boas. (...) Em muitas ocasiões encontrei cerâmica. E uma vez assisti a queima de cerâmica. Senti alguma coisa da grandeza da mãe. Eu senti tão forte aquela curva da cerâmica, tão suave, me tocou muito. (...)

Em um catálogo publicado em 2012 sobre a Exposição de Arte Kougei ${ }^{2}$ da Sociedade Brasileira de Cultura Japonesa ${ }^{3}$, Suzuki expõe de forma mais clara esse sentimento que a cerâmica lhe proporciona e a sua relação com os horrores da guerra.

No Brasil, ainda hoje, muitas pessoas me perguntam: Por que começou a fazer cerâmica? Acho que as experiências e sofrimentos durante a Segunda Guerra Mundial me levaram a pensar sobre o sentido da vida, entre outros motivos. Desde aquela época, passei a experimentar uma sensação muito especial ao estar envolvida com as cerâmicas, algo como amor, harmonia, delicadeza e de vida em si. Com as cerâmicas, sinto como se estivesse protegida por um profundo carinho materno e, ainda, tomada por um misterioso sentimento de que isso é duradouro. (SUZUKI in KAWAKAMI, 2012, p. 18).

Podemos então ver os efeitos da Segunda Grande Guerra no pensamento da jovem Suzuki, que diz ter ficado revoltada com a situação do ser humano. A experiência da guerra moldou sua trajetória como artista, assim como a de muitos outros que a vivenciaram. Depois da total destruição da casa onde morava em 1944, quando tinha 15 anos, o pai de Suzuki perdeu tudo, vindo a falecer logo após a derrota do Japão e o anúncio público de rendição do Imperador à nação em 1945. Como consequência, o país sofreu a ocupação militar norte-americana até 28 de abril de 1952, que contribuiu para a difusão de valores e padrões de comportamento americanos. Para Suzuki, a ocupação americana e a perda do pai

2. Kougei é uma palavra que literalmente significa "trabalho bem-feito", sendo a junção das palavras "habilidade" (kou) e "arte" (gei). O equivalente em inglês é craft e, em português, artes manuais ou artesanato. Yanagi Soetsu (1972: 17) define kougei como coisas feitas para serem usadas pelas pessoas no cotidiano, como roupas, mobiliário ou cerâmicas.

3. Exposição realizada desde 1968 na Sociedade Brasileira de Cultura Japonesa. A partir de 1997 mudou o nome para Exposição de Arte Craft e, em 2008, foi incorporada na Grande Exposição de Arte Bunkyô. 
implicaram ter que se mudar para a fazenda da madrasta e começar a trabalhar para ajudar o seu sustento.

Assim, na década de 50, a jovem Suzuki trabalhava ao mesmo tempo em que continuava seus estudos, contudo sem muitos resultados. Ela queria fazer alguma coisa com a mão. Naquela época, já tinha interesse por coisas antigas e seu pai sempre gostara de cerâmica e possuíra vários objetos de arte em casa. Assim, Suzuki começou a frequentar ateliês de vários artistas, entre eles o renomado ceramista e Tesouro Nacional Vivo ${ }^{4}$ do Japão Hamada Shoji (1894-1978), um dos integrantes do movimento minge $i^{5}$ No entanto, foi muito difícil encontrar um mestre que quisesse ensinar-lhe a "arte do barro" Para além da dificuldade em tornar-se discípula de um mestre devido ao sistema rígido e exigente, acrescentava-se mais um relevante impedimento: ser mulher.

\begin{abstract}
Naquela época, para professor escolher aluno era muito difícil. Não era qualquer um pagar e pronto. Eles escolhem. Daí, vida inteira, aluno é discípulo daquele professor tal, daquele ceramista tal, ou pintor. Não tinha aluna... O discípulo daquela pessoa continuava nome. Era outro modelo naquela época (...). Daí eu consegui meu professor, me aceitou, outro nunca aceitou, porque mulher não faz isso. Mulher que faz isso, ninguém acreditava. Não tinha mulher que fazia cerâmica. Conhecia só três que faziam cerâmica naquela época. Ele [o mestre que me recusou como aluna] achou um absurdo uma mulher que queria ser discípulo.
\end{abstract}

De fato, no Japão, a cerâmica é tradicionalmente uma atividade masculina, devido à força física necessária para trabalhar com os habituais fornos a lenha, como o anagama ${ }^{6}$ e o noborigama ${ }^{7}$ Segundo Todate Kazuko (2009), havia até superstições que impediam as mulheres de tocarem nos fornos, o que as restringia a trabalhos servis. O papel feminino no mundo da cerâmica era, então, o de ajudante, preparando o barro e rodando o torno de oleiro para o ceramista homem moldar as peças, como podemos ver em uma cena do famoso filme de Mizoguchi Kenji de 1953, "Contos da Lua Vaga" (Ugetsu Monogatari).

Ademais, o mundo da arte japonesa até as décadas de 1960 e 1970, além de profundamente sexista, era também extremamente hierárquico e a cerâmica

4. Título concedido pelo governo do Japão desde 1950 a determinados mestres artesãos vivos, com o objetivo de preservar habilidades técnicas e ofícios tradicionais.

5. Movimento de preservação das artes folclóricas tradicionais japonesas, fundado oficialmente em 1929 por Yanagi Sôetsu. O movimento, do qual fizeram parte os renomados ceramistas Hamada Shoji e Kawai Kanjiro, procurava a valorização dos objetos executados manualmente por artesãos anônimos.

6. Tipo de forno a lenha introduzido no Japão no século V pela China e Coreia, cuja queima dura cerca de 30 horas.

7. Tipo de forno a lenha construído em declive aproveitando a inclinação do terreno, cuja queima dura cerca de 25 horas. Foi introduzido no Japão a partir da Coreia no final do século XVI. 
japonesa fazia parte de uma lógica patriarcal na qual o conhecimento passava de pai para filho ou de mestre para discípulo. Yoshimoto (2005:2) afirma que os valores patriarcais e um sentido estrito de senioridade controlavam o mundo da arte japonesa. Até hoje, o título de Tesouro Nacional Vivo nunca foi concedido a uma ceramista mulher, apesar de várias artistas do kougei já terem sido agraciadas com esse título de honra, principalmente na área da produção de têxteis e bonecas. Assim, historicamente, as mulheres tiveram pouco acesso ao mundo da arte japonesa ou foram expostas e aceites apenas em certos tipos de arte adequados a elas, que tinham a ver com as obrigações domésticas femininas (MCDOWELL, 1999, p. 12). De fato, testemunhos arqueológicos indicam que a maioria da cerâmica feita manualmente era executada por mulheres no âmbito doméstico, enquanto a maioria da cerâmica usando torno de oleiro, produzida em oficinas, era feita por homens (TODATE, 2009).

Apesar de as mulheres japonesas terem sido excluídas da educação artística até o final da Segunda Grande Guerra, atualmente a maioria das estudantes de arte no Japão são mulheres e é cada vez mais comum ver mulheres ceramistas sendo premiadas em importantes competições (TODATE, 2009). Assim, a proliferação da educação artística possibilitou o desenvolvimento da cerâmica contemporânea, separada da lógica patriarcal e hierárquica tradicional, o que permitiu que várias ceramistas mulheres viessem a se destacar, principalmente a partir da década de 1970.

Pelos motivos apontados acima, Suzuki Shoko tinha o fato de ser jovem e mulher como principais impedimentos para se tornar discípula de um mestre ceramista. Ela conta como foi extremamente difícil entrar nesse mundo hierárquico e patriarcal e como recebeu várias recusas para ser ensinada, além de olhares de estranheza e desprezo da família. No entanto, em 1952, Suzuki conseguiu finalmente tornar-se discípula de Karasugi Toko, um reconhecido ceramista da época, à frente do seu tempo e que se tornou seu mestre durante dez anos.

Durante os primeiros tempos como aprendiz de cerâmica, Suzuki teve que trabalhar arduamente para conseguir reconhecimento entre seus pares. Por volta de 1953, por indicação de seu mestre, ela se tornou membro da associação de artistas de cerâmica, a Tokokai, cujo presidente era Itaya Hazan, um renomado ceramista da época. Lá, ela era a única mulher em um grupo com mais de 40 ceramistas homens. Yoshimoto Midori (2005, p. 11) escreve que o mundo da arte japonesa era controlado por uma estrita ordem de senioridade e das políticas entre várias outras associações de artistas geralmente conhecidas como bijutsu dantai ou kai. Assim, apesar de que as mulheres também podiam ser reconhecidas pelas suas realizações, elas estavam na base da hierarquia social, logo, para elas o escrutínio era muito mais rigoroso (BUPENDRA apud YOSHIMOTO, 2005, p. 11). Era muito difícil para as mulheres sem as conexões certas conseguirem uma posição nas associações bijutsu dantai dominadas pelos homens (YOSHIMOTO, 2005, p. 11). 


\begin{abstract}
Karasugi era muito livre. Ele me colocou em grupo de ceramistas muito importantes, alguns que já tinham recebido prêmio do imperador e do ministério. De mulher, era só eu, no meio de quarenta e tantos homens, só eu. Eles me aceitavam como amigos, mas só em encontro sobre cerâmica. Mas era outro mundo. Naquela época todo o mundo era muito rígido. Eles me respeitavam, foram sempre educados, porque eu fui escolhida por professor. Mas meus parentes achavam um horror (...). No começo era muito difícil, não tinha ceramista mulher. Queima com esse sistema era trabalho de homem. Porque era um trabalho pesada, mexer com lenha, fogo... Não tinha forno elétrico, agora tem muitas mulheres. Daí eu sempre queria liberdade.
\end{abstract}

Enquanto fez parte da Tokokai, Suzuki participou de várias exposições coletivas. Em 1955, mostrou seus primeiros trabalhos na exposição Jovens ceramistas, na Galeria Ando, em Tóquioe, entre 1956 e 1961, participou, duas vezes por ano, do salão Totoh, realizado em vários espaços, galerias e museus da capital japonesa. Entretanto, em 1958, uma de suas obras foi selecionada para uma exposição coletiva sobre arte japonesa no Museu de Hetjens, em Dusseldorf, na Alemanha.

Naquela época era quase impossível fazer exposição fora. Era outro tempo.

Em 1962, no ano em que se mudou para o Brasil, Suzuki participou de uma exposição na Galeria Yoseido, em Tóquio, intitulada Quatro mulheres ceramistas. Apesar de não termos falado sobre isso durante as entrevistas, Sumaya Mattar Moraes descreve, em sua tese de doutorado, como Suzuki Shoko se uniu a duas novas amigas ceramistas que também passavam pelas mesmas dificuldades em se afirmar como artistas por serem mulheres (MORAES, 2007, p. 47). Ela cita uma entrevista com Suzuki:

(...) Então, nós três. Eu chamava Shoko, ela chama Tioko, a outra Mioko, mas nós tiramos tudo o ko. Ko era nome de mulher. Os homens gozavam, não acreditavam. Essa letra de ko que atrapalhava nós. Então, vamos ficar igual ao nome de homem: Sho, Tio, Mio (...) (SUZUKI in MORAES, 2007: 47).

Assim, no final da década de 1950 e início de 1960, apesar da sua ascendente carreira profissional como artista de cerâmica, com ateliê individual em Tóquio e já casada com o pintor Suzuki Yukio, Suzuki Shoko não estava completamente satisfeita com sua situação e sonhava em deixar o Japão e recomeçar sua vida do zero em outro país.

Desde mocinha, depois que comecei trabalho, sempre pensei: Onde posso trabalhar com cerâmica? Não é Japão, mas outro lugar do mundo, mas eu não sei onde. Como passei por tanta coisa por causa da guerra, eu tinha muita dúvida do valor humano: por quê? Esse sentimento tomou muitas formas, até fiquei revoltada. Pensava: onde 
posso ir? No começo era tão difícil, ninguém comprava, mas daí vinha alguma pessoa e apoiava (...).

Curiosamente, na mesma época, Suzuki assistiu a um programa de televisão na NHK sobre o Brasil e se "apaixonou"

Daí justo naquela época, era 1961, eu vi uma reportagem sobre Brasil na NHK, era quase fim de 61. Daí mostrou agricultura dos imigrantes, até Liberdade, Amazonas, aqueles bichos todos, né? No fim, mostrou Brasília, as construções de Niemayer. Quando vi aquilo, eu fiquei... naquele momento... decidi naquele momento: aqui que eu tenho que ir! Parece que fogo, amor à primeira vista. No dia seguinte já comecei a vender casa, já fui na imobiliária, queria vender tudo (...). Eu queria começar do zero e não ter nada, queria me testar, vida é minha, só.

Assim, em 1962, com 32 anos de idade, Suzuki vendeu sua casa e ateliê e partiu em direção a Santos com o marido no dia 30 de março, a bordo do navio Argentina-Maru. Era a época em que o movimento do Japão para o Brasil tomava um novo rumo, pautado pela conjugação das necessidades econômicas dos dois países.

Os imigrantes japoneses que vêm depois da guerra encaixam-se dentro de um contexto em que as relações entre o Brasil e o Japão tomam novos rumos. A meta é o desenvolvimento brasileiro e a necessidade de abrir frentes para a realização deste objetivo. O Japão possui capital, tecnologia e recursos humanos. É dentro dessa equação que se pode entender a maneira como ocorreu a imigração dos japoneses no pós-guerra (SAKURAI, 2008, p. 189).

Foi neste contexto que se assistiu à transferência para o Estado de São Paulo de trabalhadores qualificados, técnicos industriais e artesãos preparados para abrir suas próprias oficinas (SAKURAI, 2008, p. 195), alguns dos quais abriram aqui suas fábricas de cerâmica. Ou seja, já não eram os imigrantes pobres do pré-guerra, que vinham para trabalhar como agricultores nas fazendas do interior de São Paulo, mas sim imigrantes especializados, atraídos pelo crescimento industrial e urbano, que se instalavam nos arredores da capital paulista.

Simultaneamente, também com início na década de 1960, um novo tipo de emigrante deixou o Japão. De acordo com Befu (2000, p. 35), não era um emigrante pobre ou que queria ficar rico no exterior, mas um emigrante que deixou o país por várias razões, incluindo uma insatisfação com a sua situação no país. Para as mulheres, a discriminação no local de trabalho foi um fator importante, já que a sociedade japonesa sempre foi tradicionalmente cruel com indivíduos considerados marginais. Outros, de espírito mais aventureiro, deixaram o Japão sem qualquer motivo relevante, mas apenas por uma curiosidade de conhecer lugares exóticos ou em busca de uma vida que lhes proporcionasse um sentimento de satisfação que não poderiam encontrar no Japão. Foi o caso de Suzuki Shoko e de muitos outros 
artistas que imigraram para o Brasil nas décadas de 1960 e 1970, impulsionados pela busca de maior liberdade e por uma visão romântica da vida nos trópicos.

\begin{abstract}
Eu adoro música latino-americana, não sei por que, era tão alegre! (...) Eu acho que tinha alguma razão para eu vir para cá.
\end{abstract}

Suzuki Masatake ${ }^{8}$ afirma que os artistas japoneses vislumbravam no "Novo Mundo" um lugar desafiante pelo qual alimentavam esperança e certo romantismo. A escolha do Brasil mostrou-se a mais interessante e promissora por ser o país estrangeiro mais familiar, que permitia uma maior proximidade à terra natal devido à forte presença da comunidade japonesa, ao mesmo tempo que possibilitava uma exploração e desbravamento artístico impossíveis de alcançar no Japão (MORAIS, 2010, p. 16). De fato, quando questionada se teria conseguido desenvolver seu trabalho da mesma forma no Japão, Suzuki Shoko respondeu, entre gargalhadas: Não, impossivel!

Após a chegada ao Brasil, o casal Suzuki alugou uma casa de pau a pique em uma mata chamada Sertãozinho, em Mauá, onde já se estabelecera, em 1960, a fábrica de porcelanas Mizuno, que se mantém em funcionamento até os dias de hoje. Com a ajuda do senhor Mizuno, Suzuki conseguiu conselhos e o apoio necessário para iniciar seu trabalho em cerâmica.

\begin{abstract}
Aluguei uma casinha de caboclo, bem pequenininha, pau a pique que fala, né? Ali que comecei, descalça. Eu andava sem nada, sozinha. Não tinha ninguém, só caboclos (...). Caboclos sempre andam descalços e eu também queria começar assim.
\end{abstract}

Lá instalou seu torno manual (te-rokuro) e começou a explorar vários tipos de argilas e esmaltes de cinzas vegetais, que se tornariam sua "marca" como ceramista. Seu objetivo, desde o início, sempre foi utilizar matéria-prima brasileira.

Precisa ter característica brasileira, não adianta a mesma coisa do Japão aqui. (...) Eu queria usar só coisa do Brasil. (...) Aqui tem terra muito rica, cultura muito rica também.

Em 1964, o casal Suzuki comprou um terreno em Cotia e iniciou a construção de sua casa. Ao mesmo tempo, Suzuki Shoko começou a construir sozinha e com suas próprias mãos um forno a lenha tradicional japonês, um noborigama.

Eu ia construir [meu próprio forno no Japão]. Mas meu professor chamou amigos também, que vieram me ajudar a construir. Num dia e pouco ficou pronto. (...) Mas

8. Declaração obtida em entrevista realizada em Abril de 2010 na Sociedade Brasileira de Cultura Japonesa. 
eu pensei: quando eu fizer segundo forno noutro país, novo mundo, eu vou fazer um por um comigo, sozinha. (...)

Eu não ia fazer forno noborigama no Brasil. Mas meu amigo me deu projeto dele. No Japão, era tradição muito rigorosa. Ele era aluno de pessoa muito importante no Japão. Daí, ele me deu esse projeto, me disse: "leva esse, talvez te ajude". (...). Daí, quando eu comprei esse terreno, era inclinado e pensei: aqui é bom fazer noborigama, então vou fazer aquele que amigo me deu. Ele disse assim... geralmente isso era muito segredo, naquela época, ceramista com nome conserva segredo, então ele disse: "esse forno eu vou dar, porque você vai para o fim do mundo, esse é só para você!" Então eu lembrei dele e pensei: vou usar esse aqui. Tamanho do forno é pequenino e inclinamento [do terreno] é exatamente para aquele forno.

No final de 1965, quando terminou a construção do forno com tijolos usados e toras de madeira doadas pelos amigos, Suzuki batizou-o de Saigama, como era costume no Japão.

Ceramista antigo colocava muito nome no forno, como se fosse vivo. Como se fosse gente. Até forno tinha essa tradição no Japão.

Em 1967, após várias tentativas insatisfatórias, Suzuki finalmente conseguiu os resultados desejados e mostrou seu trabalho pela primeira vez no Brasil em uma exibição em seu ateliê, que juntou cerca de 800 pessoas da comunidade artística nikkei, dando início à sua ascendente carreira como reconhecida artista de cerâmica. No ano seguinte, já começou a participar da Exposição de Arte Kougei, realizada anualmente na Sociedade Brasileira de Cultura Japonesa com o objetivo de divulgar a arte kougei no Brasil.

Uma vez eu recebi uma senhora chamada Yazima Sada. Ela disse que precisa fazer exposição, aqui tem alguns artistas da área do kougei que precisa juntar, tem que fazer. Daí eu falei que eu participei tanto no Japão, eu vim para cá porque eu não queria mais participar de nada. Eu não quero. Mas ela insistia tanto. Daí,mudei de ideia. Se for assim, com pessoas importantes, eu vou participar. Só que eu vou colocar melhor obra do ano nessa exposição, isso eu queria. Mas eu não posso participar do movimento, cuidar dessas coisas, não é meu jeito. Eu só fico no meu cantinho, trabalhando. (...) Eu não queria [participar das exposições da comunidade nikkei] porque lá [no Japão] participei muito, mas pessoa era tão tradicional, nunca mais. Me livrei tudo! (...) Eu queria começar do zero, queria ver até onde eu posso fazer.

Assim, apesar das tentativas de se afastar das amarras da tradição japonesa, Suzuki acabou entrando na comunidade artística nikkei e se envolvendo na divulgação dessa mesma tradição no Brasil. Contudo, ela sempre evitou fechar-se na "colônia", aproveitando todas as oportunidades para abrir a exposição ao 
público e artistas brasileiros. Deste modo, na edição de 1997, que recebeu a visita do Imperador do Japão, Suzuki sugeriu a mudança do título da exposição para Exposição de Arte Craft, que considerava um termo mais universal que arte kougei, especificamente japonês.

Nós viemos aqui, não é para ser, divulgar, japoneses. Precisamos entrar nessa cultura brasileira (...). Tem que ser internacional, universal.

A partir de 1968, além de participar em exposições coletivas, Suzuki realizou também várias exposições individuais em São Paulo, Rio de Janeiro e Curitiba. Em 1975, com 46 anos de idade, apresentou suas obras no Museu de Arte de São Paulo (MASP), em uma mostra individual que ocupou todo o segundo andar do museu, constituindo-se como um dos pontos mais altos da sua carreira. Em 1984, conheceu finalmente as construções de Niemayer em Brasília, quando realizou uma exposição na Fundação Cultural do Distrito Federal sob o apoio da Galeria Toki Arte. Finalmente, em 2003, em comemoração aos seus 50 anos como ceramista, apresentou o conjunto da sua obra no Museu da Casa Brasileira. Foi nessa ocasião que conheceu a jovem ceramista Ivone Shirahata, que se tornaria sua discípula.

Eu tenho que passar para alguém para não acabar. Mas não é todo o mundo que tem aquela paciência para que, treinando, chegar lá. Sempre Ivone estava nas exposições, então convidei ela para aprender.

Na época com 74 anos e com uma carreira já de meio século, Suzuki sentiu a necessidade de passar o seu conhecimento para as gerações mais jovens. A eminência da desativação do seu forno noborigama devido à sua idade avançada trouxe um desejo de deixar um registro físico da sua história no Brasil. Assim, entre 2004 e 2006, Suzuki ensinou a Shirahata as técnicas tradicionais japonesas pelas quais se tornou conhecida no Brasil: modelagem em torno manual (te-rokuro), queima em forno a lenha noborigama e esmaltação da superfície das peças de cerâmica com vidrados de cinzas vegetais. E, em 2006, usando o mesmo projeto arquitetônico que lhe fora dado por um amigo ceramista no Japão quatro décadas antes, Suzuki e Shirahata iniciaram a construção do terceiro kama $^{9}$

Quando eu vi Ivone, senti alguma coisa espiritual, que tenho que deixar essa técnica de torno manual para alguém. Alguém tem que saber (...). Se desmontar aquele [noborigama] não existe mais, tem que ter (...). Estou leve, agora estou muito leve que passei para ela. (...) Aqui posso dizer eu fiz terceiro kama. É muito importante mostrar, continuar.

9. Kama significa "forno de cerâmica" em japonês. 


\section{Considerações finais}

Tal como Suzuki Shoko, muitos dos ceramistas japoneses que imigraram para o Brasil nas décadas de 1960 e 1970 trouxeram um processo tradicional e uma visão do mundo que, a olhos não japoneses, constituem-se como "tradicionalmente nipônicos". Apesar da sua vinda para o país estar relacionada com uma busca de maior liberdade artística ao escapar do rigor da tradição japonesa, estes artistas apropriaram-se da mesma tradição à qual tentavam escapar e preocuparam-se em divulgá-la e ensiná-la às gerações mais jovens.

Eu não pensei [em manter a tradição japonesa de cerâmica], mas está comigo, parece que a raiz está aqui, que não posso fugir, está sempre atrás de mim. Mas no começo penso que queria jogar tudo e começar de novo, mas é dificil, aprendi que sangue é coisa boa. Agora estou agradecida.

No entanto, esta "tradição" que Suzuki considera inerente ao seu ser é uma herança nipônica apreendida no seio da cultura e sociedade japonesas. Transcrevendo as palavras de Katia Canton (2009, p. 57), podemos ver como $o$ tempo da memória, afinal, não é apenas o tempo que já passou, mas o tempo que nos pertence. Ou seja, essa "identidade japonesa", historicamente construída e politicamente marcada, que implicou na "invenção" de tradições e que está presente no discurso e na prática desta ceramista, transforma-se de simulacro incutido por um sistema de formadores de opinião, utilizando a metáfora do mito da caverna de Platão, em realidade, apropriada e transformada pelas experiências pessoais desta ceramista. Todavia, sua trajetória, marcada pela vivência transcultural, gerou uma identidade híbrida, um interstício entre o Japão e o Brasil.

\footnotetext{
Quando eu voltei [para o Japão], ela [antiga amiga ceramista] falou assim: Porque você saiu correndo para o Brasil? Parecia que pegou fogo no rabo. Eu disse: Me apaixonei, né? Daí ela começou a falar do meu trabalho e disse: Você não é mais japonesa. Eu fiquei tão feliz, assim. Eu queria ficar no meio. Por isso que quis sair do Japão (....) Eu queria aprender pisando no chão, sozinha, absorvendo. Daí, fiquei muito contente.
}

A situação de estar no meio de duas culturas, coloca esta ceramista não em um espaço vácuo, em que não pode ser nem uma coisa nem outra, mas em um lugar de múltiplas possibilidades, na qual ambas as identidades, japonesa e brasileira, são realidades simultâneas, situacionais e simbólicas.

Deste modo, a tradição japonesa apropriada por Suzuki Shoko, ao invés de manter-se incólume e estática, recebe uma tradução pessoal, transcultural e nipo-brasileira, constituindo-se como algo fluído, em constante transformação e historicamente marcado, como o são todos os processos culturais. Pois, tal como 
Julio Plaza (2003, p. 2) afirma, o passado não é apenas lembrança, mas sobrevivência como realidade inscrita no presente.

\section{Referências Bibliográficas}

BEFU, Harumi. Globalization as Human Dispersal. In EADES, J. S.; GILL, T.; BEFU, H. Globalization and Social Change in Contemporary Japan. Melbourne: Trans Pacific Press, 2000.

BERTAUX, Daniel. Les Récits de Vie. Paris: Éditions Nathan, 1997.

CANTON, Kátia. Tempo e Memória. São Paulo: Martins Fontes, 2009.

HALL, Stuart. A Identidade Cultural na Pós-Modernidade. Rio de Janeiro: DP\&A Editora, 1992.

HOBSBAWM, Eric; RANGER, Terence. A Invenção das Tradições. Rio de Janeiro: Paz e Terra, 1984.

KAWAKAMI, Hisako (coord.). Raízes da Arte Kougei no Brasil. São Paulo: Fundação Kunito Miyasaka, 2012.

MCDOWELL, Jennifer. Japanese Women and their connection to the craft movement and craft production in Japan. Lambda Alpha Journal. Kansas: Wichita State University, 1999. v. 29. p. $12-28$.

MORAES, Sumaya Mattar. Descobrir as texturas da essência da terra: formação inicial e práxis criadora do professor de arte. Tese de doutorado. São Paulo: ECA-USP, 2007.

MORAIS, Liliana. A cerâmica japonesa no Brasil: contexto histórico e modificações socioeconômicas que permitiram sua produção e demanda no Estado de São Paulo no pós-guerra. In: Estudos Japoneses, São Paulo, 2010. n. 30. p. 33-48.

ORTIZ, Renato. O Próximo e o Distante. São Paulo: Editora Brasiliense, 2000.

PLAZA, Julio. Tradução Intersemiótica. São Paulo: Editora Perspectiva, 2003.

SAKURAI, Célia. A Imigração dos Japoneses para o Brasil no Pós-Guerra (1950-1980). In: HASHIMOTO, F.; TANNO, J. L.; OKAMOTO, M. S. Cem Anos da Imigração Japonesa. São Paulo: Editora Unesp, 2008. p. 307-319.

TODATE, Kazuko. The History of Japanese Women in Ceramics. In NICOLL, J.; WAHEI, A.; TODATE, K.; MORESE, S. C. Touch Fire: Contemporary Japanese Ceramics by Women Artists. Northampton, MA: Smith College Museum of Art, 2009. Disponível em: $<$ http://www.smith.edu/artmuseum2/archived_exhibitions/touchfire/from_the_catalogue. $\mathrm{htm}>$. Acesso em: 24 set. de 2012.

YANAGI, Soetsu. The Unkown Craftsman: a Japanese Insight into Beauty. 1. ed. Tokyo: Kodansha International LTD., 1972.

YOSHIMOTO, Midori. Into Performance: Japanese Women Artists in New York. New Brunswick/ New Jersey/ London: Rutgers University Press, 2005. 